\title{
T-Cell Infiltration and Signaling in the Adult Dorsal Spinal Cord Is a Major Contributor to Neuropathic Pain-Like Hypersensitivity
}

\author{
Michael Costigan, ${ }^{3 *}$ Andrew Moss, ${ }^{1 *}$ Alban Latremoliere, ${ }^{3 \star}$ Caroline Johnston, ${ }^{2}$ Monica Verma-Gandhu, ${ }^{3}$ \\ Teri A. Herbert, ${ }^{3}$ Lee Barrett, ${ }^{3}$ Gary J. Brenner, ${ }^{3}$ Daniel Vardeh, ${ }^{3}$ Clifford J. Woolf, ${ }^{3}$ and Maria Fitzgerald ${ }^{1}$ \\ ${ }^{1}$ UCL Department of Neuroscience, Physiology \& Pharmacology and ${ }^{2}$ UCL Department of Biochemistry, University College London, London WC1 EBT, \\ United Kingdom, and ${ }^{3}$ Neural Plasticity Research Group, Massachusetts General Hospital, Charlestown, Massachusetts 02129
}

Partial peripheral nerve injury in adult rats results in neuropathic pain-like hypersensitivity, while that in neonatal rats does not, a phenomenon also observed in humans. We therefore compared gene expression profiles in the dorsal horn of adult and neonatal rats in response to the spared nerve injury (SNI) model of peripheral neuropathic pain. The 148 differentially regulated genes in adult, but not young, rat spinal cords indicate a greater microglial and T-cell response in adult than in young animals. T-cells show a large infiltration in the adult dorsal horn but not in the neonate after SNI. T-cell-deficient Rag1-null adult mice develop less neuropathic mechanical allodynia than controls, and central expression of cytokines involved in T-cell signaling exhibits large relative differences between young and adult animals after SNI. One such cytokine, interferon- $\gamma($ IFN $\gamma)$, is upregulated in the dorsal horn after nerve injury in the adult but not neonate, and we show that IFN $\gamma$ signaling is required for full expression of adult neuropathic hypersensitivity. These data reveal that T-cell infiltration and activation in the dorsal horn of the spinal cord following peripheral nerve injury contribute to the evolution of neuropathic pain-like hypersensitivity. The neuroimmune interaction following peripheral nerve injury has therefore a substantial adaptive immune component, which is absent or suppressed in the young CNS.

\section{Introduction}

Most animal models of peripheral neuropathic pain involve partial nerve injury and manifest with hypersensitivity to noxious and non-noxious stimuli in the neighboring spared territory (Bennett and Xie, 1988; Seltzer et al., 1990; Kim and Chung, 1992; Decosterd and Woolf, 2000). However, these models do not distinguish the cellular and molecular pathways specifically responsible for initiating and maintaining neuropathic painlike hypersensitivity (Costigan et al., 2009) from the more general consequences of nerve damage, including the nerve regeneration response and the cellular stress response associated with altered metabolic and survival pathways. We have exploited the observation that partial nerve injury in rats from birth to the age of 3 weeks does not produce mechanical hypersensitivity (Howard et al., 2005; Ririe and Eisenach, 2006) to tease out what is responsi-

Received Sept. 15, 2009; accepted Sept. 25, 2009.

This work was supported by the National Institutes for Health (DE017821), the Medical Research Council, UK, and the Wellcome Trust Pain Consortium. A.M. was the recipient of a Bogue research fellowship. A.L. was the recipient of a Fondation pour la Recherche Medicale fellowship.

*M.C., A.M., and A.L. contributed equally to this work.

Correspondence should be addressed to either of the following: Michael Costigan, Neural Plasticity Research Group, Massachusetts General Hospital, 149 13th Street, Charlestown, MA 02129, E-mail: costigan@helix. mgh.harvard.edu; or Andrew Moss at his present address: Pain Biology, Pfizer Global Research and Development, Ramsgate Road, Sandwich, Kent CT13 9NJ, UK, E-mail: andrew.moss@pfizer.com.

C. Johnston's present address: Institute of Psychiatry, King's College London, 125 Coldharbour Lane, London SE5 9NU, UK.

DOI:10.1523/JNEUROSCI.4569-09.2009

Copyright $\odot 2009$ Society for Neuroscience $\quad$ 0270-6474/09/2914415-08\$15.00/0 ble for producing peripheral neuropathic mechanical allodynia in mature animals.

Genes with altered expression in the dorsal horn of the adult rat spinal cord following peripheral nerve injury have been characterized by microarray expression profiling (Yang et al., 2004; Lacroix-Fralish et al., 2006; Griffin et al., 2007). On comparing three neuropathic pain models [spared nerve injury (SNI), spinal nerve ligation (SNL), and chronic constriction injury (CCI)] over 6 weeks, we found that the most prevalent functional class of regulated genes in the dorsal horn across all models were from the immune system (Griffin et al., 2007).

Microglia in the dorsal horn of adult animals contribute to the generation of neuropathic hypersensitivity, a process that involves their recruitment, proliferation, and activation (Watkins et al., 2001; DeLeo et al., 2004; Tsuda et al., 2005; Zhuang et al., 2005; Griffin et al., 2007; Ji and Suter, 2007; Echeverry et al., 2008; Kawasaki et al., 2008). In the dorsal horn of young rats, the microglial response to peripheral nerve injury is considerably less than that in adults, and this may contribute to differences in pain-like hypersensitivity in young and adult animals (Moss et al., 2007; Vega-Avelaira et al., 2007). To define the contribution of this and other mechanisms, we have used genome-wide expression arrays to determine differential changes in gene expression in the dorsal horn following peripheral nerve injury in neonatal and adult rats. In a two-way design using SNI and a sham operation in young and adult animals, we hypothesized that we could identify genes specifically associated with the manifestation of the neuropathic hypersensitivity phenotype. Of the 
genes that we find are expressed in response to nerve injury in adult animals but not in young animals, most are immune related, and they include numerous genes involved in T-cell signaling. Based on this, we first confirm that infiltrating T-cells are involved in driving neuropathic mechanical hypersensitivity in the adult (Cao and DeLeo, 2008) and then show that T-cell infiltration is absent in the neonatal dorsal horn following SNI. We conclude that infiltration of T-cells into the spinal dorsal horn in mature animals after nerve injury plays a critical role in the evolution of pain-like hypersensitivity in this condition.

\section{Materials and Methods}

Animal surgery. Adult male and $10 \mathrm{~d}$ old (P10) Sprague Dawley rats were anesthetized using isoflurane (2-4\%), and SNI surgery was performed where the tibial and common peroneal branches of the sciatic nerve were tightly ligated with a silk suture and transected distally, while the sural nerve was left intact (Decosterd and Woolf, 2000). In sham-operated controls, the sciatic nerve was exposed but not ligated. The wounds were closed and the animals returned to their cages or litters. Adult Rag1-null, interferon- $\gamma($ IFN $\gamma$ ) receptor 1 (IFN $\gamma R$ 1)-null, nude, B-cell-deficient, and littermate control mice were subject to the same procedures (The Jackson Laboratory). Rag1-null and IFN $\gamma R 1$-null mice were bred on a C57BL/6j background and backcrossed at least 10 times. In the United Kingdom, all experimental procedures were specifically licensed and approved by the UK Home Office, and in the United States, all procedures were performed in accordance with the Massachusetts General Hospital animal care regulations.

Tissue preparation, RNA extraction, and chip hybridization. The L4 and L5 lumbar dorsal horns ipsilateral to injury were dissected and rapidly frozen. The tissues were homogenized and total RNA was obtained by acid phenol extraction (TRIzol reagent, Invitrogen). Biotinylated cRNA for hybridization was produced from the total RNA and hybridized to the Affymetrix Rat RAE230A chip (Affymetrix) (Costigan et al., 2002). For each condition, six biologically independent hybridizations were performed, and individual RNA samples were extracted by pooling either four adult or six P17 ipsilateral dorsal horns.

Array data analysis. Array CEL files (Affymetrix.com) were analyzed using Bioconductor tools in $\mathrm{R}$ [bioconductor.org (Gentleman et al., 2004); R-project.org (R Development Core Team, 2005)]. Data were normalized with gcRMA (Wu et al., 2004). Differential expression was tested with Limma using the Benjamini-Hochberg false discovery rate (FDR) (Smyth, 2005). Genes significantly regulated in the adult but insignificantly regulated in the young animals, the $\mathrm{Ad} 0.05 / \mathrm{Ne} 0.9$ list, were determined as follows: sham versus SNI FDR $<0.05$ in the adult and sham versus SNI FDR $>0.9$ in the neonate. All lists generated are given as supplemental tables (available at www.jneurosci.org as supplemental material). The Ad0.05/Ne0.9 gene list was analyzed with IPA version 6.0 software (Ingenuity Systems) to identify functional pathways represented within the dataset.

Quantitative real-time PCR. Ipsilateral L4/L5 dorsal horn tissue and RNA extracted from animals were distinct from those used for the array hybridizations. Before reverse transcription (RT), genomic DNA was removed from the RNA samples using TURBO DNA-free DNase I (Ambion). Quantitative real-time PCR was performed using the Sybr green detection system with primer sets designed on Primer Express. Specific PCR product amplification was confirmed using dissociation protocol. Transcript regulation was determined using the relative standard curve method per the manufacturer's instructions (Applied Biosystems). Relative loading was determined before RT with RNA spectrophotometry followed by gel electrophoresis and after RT by amplification of glyceraldehyde-3-phosphate dehydrogenase. For each time point, at least three samples of pooled tissue from at least two animals per sample were analyzed.

Immunohistochemistry. Terminally anesthetized rats were perfused $(0.9 \% \mathrm{NaCl})$ followed by $4 \%$ paraformaldehyde/PBS. Lumbar spinal cord was postfixed (4\% paraformaldehyde/PBS) and then stored in $30 \%$ sucrose, $\mathrm{PBS}$, and $0.02 \%$ sodium azide at $4^{\circ} \mathrm{C}$. Staining was performed on $40 \mu \mathrm{m}$ free-floating cryosections, blocked for $1 \mathrm{~h}$ in $0.05 \mathrm{M}$ Tris, $\mathrm{pH} 7.4$,

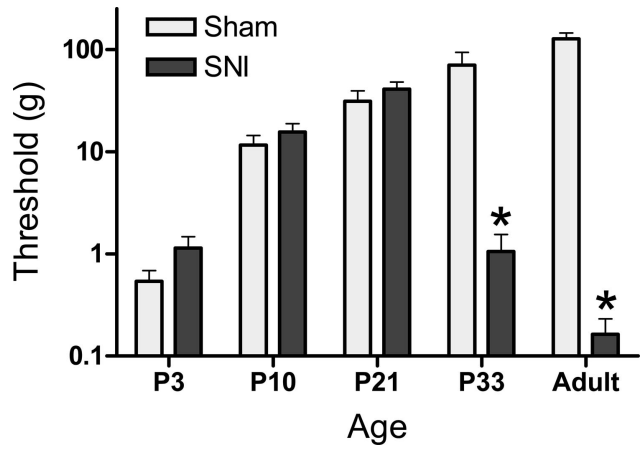

Figure 1. Mechanical thresholds to von Frey hindpaw testing $7 \mathrm{~d}$ after SNI or sham surgery. Surgery was performed at P3, P10, P21, or P33. Only animals operated at P33 and adults displayed the mechanical hypersensitivity characteristic of a neuropathic pain-like response. Data are expressed as mean response threshold \pm SEM. ${ }^{*} p<0.05$, two-way ANOVA, $n=5$ animals at each age.

$0.3 \%$ Triton X-100, and 5\% normal goat serum (TTBS-NGS). Sections were incubated $\left(72 \mathrm{~h}, 4^{\circ} \mathrm{C}\right)$ in TTBS-NGS with primary antibody, i.e., 1:100 mouse anti-CD2 (Serotec) and 1:1000 rabbit anti-Iba (Wako Chemicals) antibody. They were then washed (PBS) and incubated with 1:500 biotinylated anti-mouse secondary antibody (Vector Laboratories). Fluorescent Cy3-streptavidin or FITC-labeled secondary antibodies were from Jackson ImmunoResearch Laboratories. For T-cell counting, serial $30 \mu \mathrm{m}$ sections were cut and mounted throughout the lumbar cord of naive as well as SNI P17 and adult rats ( $n=3$ per group). $\mathrm{CD} 2$ antibody staining (as above).

Animal behavior. All behavior, unless stated, was performed blind and when appropriate against sham controls. For rat neonatal and adult mechanical allodynia, hindlimb flexion withdrawal thresholds to mechanical stimulation were determined using calibrated von Frey hairs (Howard et al., 2001). The stimulus was applied to the dorsal surface of the hindpaw three times at $1 \mathrm{~s}$ intervals for each strength, starting at the lowest, until a reflex was elicited. Mechanical sensitivity in the nude and B-cell-deficient lines was also assayed with this protocol, although these two mouse strains were not assayed blind. Other mouse mechanical allodynia assays (Rag1 and IFN $\gamma R 1$ null) were tested against wild-type littermate controls; these animals were assayed using von Frey calibrated filaments (0.008-2 g; Stoelting) with withdrawal threshold determined as the filament at which the animal withdraws its paw at least three times in 10 applications (Decosterd and Woolf, 2000). Baseline behavioral tests were performed before and then on the days indicated after nerve injury.

\section{Results}

Young animals do not develop mechanical hypersensitivity following partial peripheral nerve injury

SNI performed before $\mathrm{P} 21$ had no significant effect upon hindpaw mechanical hypersensitivity, in contrast to the marked effects that are produced when the procedure was performed in rats $>3$ weeks old (Fig. 1). Functional nociceptive pathways are present, however, and can be sensitized by peripheral inflammation before P21 (Hedo et al., 1999; Torsney and Fitzgerald, 2002; Walker et al., 2005), indicating that absence of mechanical hypersensitivity in young animals is specific to nerve injury and not a generalized sensory deficiency.

\section{Expression profiles in the dorsal horn after partial peripheral nerve injury in young versus adult rats}

We used oligonucleotide microarrays to detect relative changes in mRNA expression in the ipsilateral dorsal horn of young (P10 rat pups) and adult rats $7 \mathrm{~d}$ after SNI, compared with sham surgery. Global expression profiles were derived from an average of six arrays for each time point, for full array data see GEO database (http://www.ncbi.nlm.nih.gov/geo/, accession number 


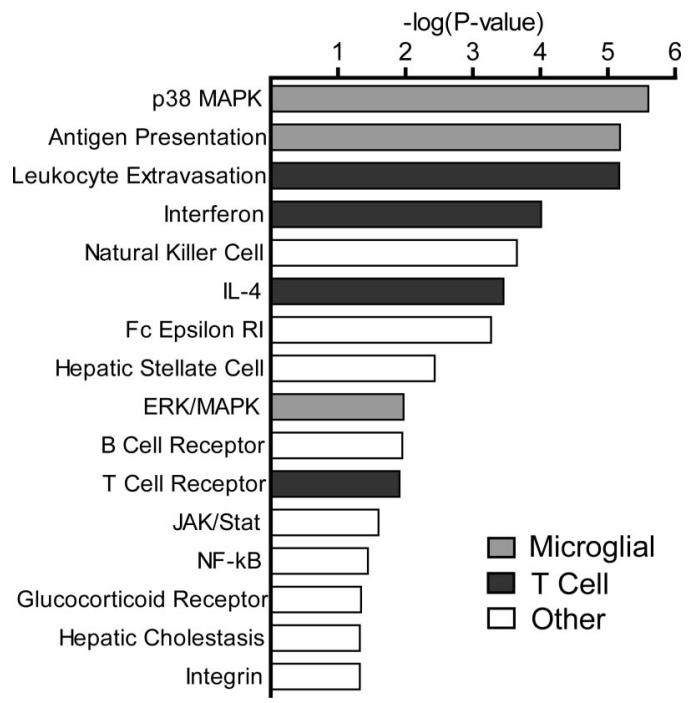

Figure 2. Canonical pathway analysis of signaling cascades associated genes regulated in the adult but not the neonate dorsal horn ( $\mathrm{Ad0} 0.05 / \mathrm{Ne} 0.9$ gene list) using Ingenuity Pathway Analysis. Bars represent the $\operatorname{LD}[-\log (p$ value $)]$ for that pathway being overrepresented within the gene list (right-tailed Fisher's exact test). LOD 1.3 ( $p$ value of 0.05 ) threshold used. Gene functional categories primarily representing microglial cell function and T-cell function are shown.

GSE18803). We defined regulated genes with Limma using the Benjamini-Hochberg FDR paradigm and set the cutoff at 0.05 to minimize false positives. A comparison of the genes detected in the ipsilateral dorsal horn $7 \mathrm{~d}$ after SNI but not in sham revealed 22 regulated genes in the neonatal dorsal horn $(0.2 \%$ of total $)$ and 188 genes in the adult (1.9\% of total) (supplemental Tables 1 and 2 , respectively, available at www.jneurosci.org as supplemental material). Of these, all were upregulated following neonatal nerve injury, and 98\% were upregulated and 2\% downregulated in the adult. To identify genes whose expression changed in the adult but not in the neonate, we compared those regulated in the adult (adjusted $p$ value $<0.05$ ) with those with an adjusted $p$ value $>0.9$ in the neonate (the Ad0.05/ Ne0.9 list) (supplemental Table 3, available at www.jneurosci.org as supplemental material). Of the 188 genes regulated in the adult dorsal horn, 148 (79\%) displayed no or minimal regulation in the neonate.

Genes differentially regulated between the adult and young dorsal horn following nerve injury are immune related Analysis of the 148 differentially regulated genes with Ingenuity pathway analysis software (Ingenuity Systems) revealed nine "Function and Disease" categories with LOD $[-\log (p$ value $)]$ scores above 10 (equivalent to $p$ values $<1 \times 10^{-10}$ ), of which five were related to immune function (supplemental Fig. 1, available at www.jneurosci.org as supplemental material). These data support our hypothesis that differences in the immune response contribute, following peripheral nerve injury, to absence of mechanical hypersensitivity in the neonate and its presence in the adult. Canonical pathway analysis of potential signaling mechanisms within the Ad0.05/Ne0.9 list reveals many cascades that likely reflect an enhanced microglial response to peripheral nerve injury in the adult dorsal horn relative to the neonate, including p38 (Ji and Suter, 2007), antigen presentation (Moss et al., 2007), and Erk (Zhuang et al., 2005) (Fig. 2). The microglial marker CD68, for example, is upregulated to a much lesser extent in the neonatal dorsal horn relative to the adult following SNI (Fig. 3a). These data are in agreement with other genes with a known or

\section{a CD68 (Microglial)}

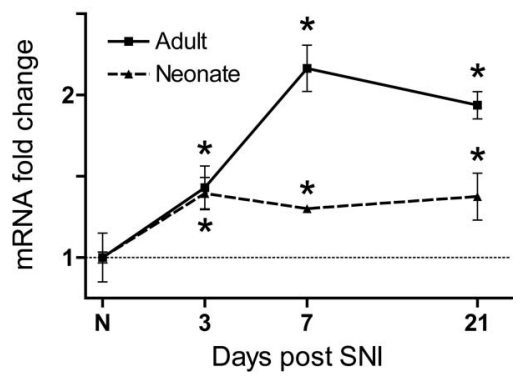

b $\quad$ CD2 (T cell)
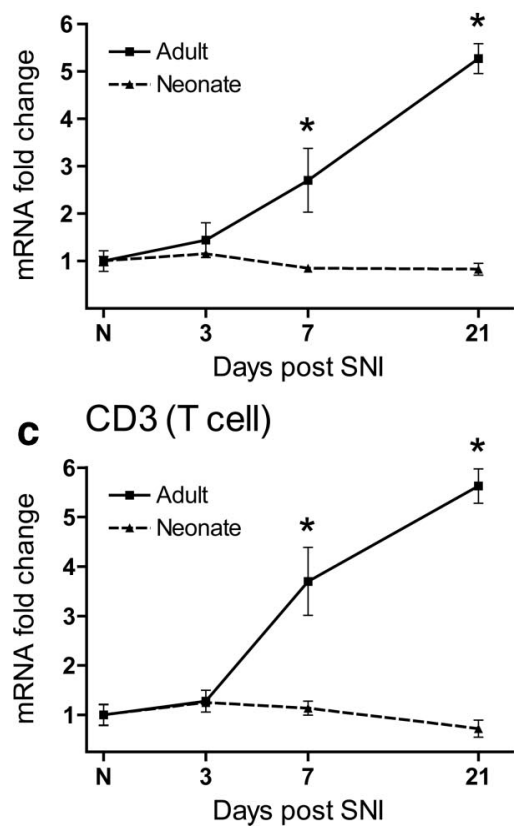

Figure 3. a, Quantitative PCR analysis of CD68 mRNA expression in the neonatal and adult rat dorsal horn over time after SNI relative to age-matched controls and uninjured animals, respectively. $\boldsymbol{b}, \boldsymbol{c}, \mathrm{CD} 2(\boldsymbol{b})$ and $\mathrm{CD} 3$ (c) transcripts increase successively over time in the adult rat dorsal horn relative to uninjured animals, but do not change in the neonatal dorsal horn relative to age-matched controls. Data are expressed as mean fold \pm SEM. ${ }^{*} p<0.05$, one-way ANOVA, Student's $t$ test, $n=4$ per group.

presumed function in microglia (Moss et al., 2007). In the adult, genes that are primarily expressed in microglia, are generally upregulated, peaking at 3-7 d after nerve injury (Fig. 3b) (Griffin et al., 2007; Moss et al., 2007).

One nonmicroglial signaling pathway identified from the Ingenuity analysis is that associated with T-cell signaling (Fig. 2), pointing to a possible role for T-lymphocytes in the differential response of the neonate and adult dorsal horn to peripheral nerve injury. The presence of components of leukocyte extravasation and interferon and IL4 signaling among the differentially regulated genes also suggests T-cell involvement (Fig. 2). Of genes present in the "interferon signaling" category, all were members of the IFN $\gamma$ pathway (results not shown); IFN $\gamma$ and IL4 are hallmark cytokines of the Th1 and Th2 T helper cells, respectively. As $\mathrm{T}$-cells originate from hematopoietic stem cells in bone marrow and only divide in the thymus, increased levels of these cells in the adult spinal cord must be due to an infiltration from the blood stream via leukocyte extravasation (Engelhardt, 2006).

To investigate whether there is an age-dependent involvement of T-cells in the spinal cord in response to nerve injury, we assayed the T-cell-specific markers CD2 and CD3 in the dorsal 
horn of neonates and adults after SNI. CD2 and CD3 increased their expression over time in the adult dorsal horn following SNI, in contrast to the neonate, in which expression was not altered (Fig. 3b,c).

T-cells infiltrate the adult but not the neonatal dorsal horn following injury To determine the extent and distribution of T-cell infiltration in the spinal cord after adult or P10 SNI surgery, we used CD2 immunohistochemistry. T-cells were detected after SNI in the adult dorsal horn. Staining with Ibal in the same section, showed activation of microglia in the same general area as CD2-positive T-cells (Fig. 4a). T-cells were mainly located within the topographic region of the lumbar dorsal horn occupied by the injured nerve central terminals (Fig. 4b), in common with activated microglia (Beggs and Salter, 2007). The number of CD2-positive T-lymphocytes per tissue section increased 10-fold in the ipsilateral adult dorsal horn relative to naive animals. A modest but significant increase was observed in the dorsal horn contralateral to SNI, compared with naive rats. In contrast, very few CD2-immunopositive profiles were observed in the dorsal horn of neonatal animals (Fig. 4c). In naive P10 rats, the numbers of CD2-positive T-cells were equivalent to naive adults $(2.2 \pm$ 0.05 vs $2.0 \pm 0.05$, respectively), but did not significantly increase following SNI (Fig. 4c).

T-cell infiltration into the adult dorsal horn contributes to the onset of neuropathic pain-like hypersensitivity To test whether $\mathrm{T}$-cell infiltration into the adult spinal cord contributes to the establishment of neuropathic pain-like hypersensitivity, we assayed mechanical threshold following SNI in a T-lymphocyte-deficient mouse strain, the Rag1 null on a C57BL/6j background. Rag1-null mice displayed significantly less mechanical hypersensitivity than wild-type littermate controls in the SNI model over a 3 week time course, with this effect proving more marked at later time points (Fig 5). In addition, two independent Rag1-null mice substrains showed similar reduced SNI-induced mechanical sensitivity compared with C57BL/6j mice (data not shown).

Cao and DeLeo (2008) recently showed a reduction in neuropathic hypersensitivity in T-cell-deficient nude mice using the L5 spinal nerve transection model. We obtain similar findings for the SNI model in the nude mouse (supplemental Fig. 2, available at www.jneurosci.org as supplemental material). Because both the nude and Rag1-null animals are also deficient in B-lymphocytes, we next tested whether B-cell-deficient animals develop neuropathic mechanical allodynia. In contrast to T-celldeficient animals, the B-cell-deficient mice developed mechanical hypersensitivity following peripheral nerve injury (supplemental
Fig. 2, available at www.jneurosci.org as supplemental material), consistent with the reported lack, using FACS sorting, of B-cell infiltration into the spinal cord in the L5 spinal nerve transection model (Cao and DeLeo, 2008). Together, the data presented here and those of Cao and DeLeo (2008) define infiltrating T-lymphocytes as contributing to neuropathic mechanical hypersensitivity in adult animals.

\section{Cytokines indicative of T-cell signaling are differentially} expressed in the adult relative to the neonatal dorsal horn T-cells have different functional subtypes, including helper and cytotoxic T-cells. Cytotoxic T-cells express CD4 and CD8, both of which are preferentially expressed in the adult dorsal horn after SNI relative to the neonate (supplemental Fig. 3, available at www.jneurosci.org as supplemental material). However expression of CD4 and CD8 could also arise from macrophage/microglia and NK cells, and involvement of cytotoxic T-cells is not seen by FACS analysis (Cao and DeLeo, 2008). Both IFN $\gamma$ and IL4 signaling are defined by the array data as present in the adult but 


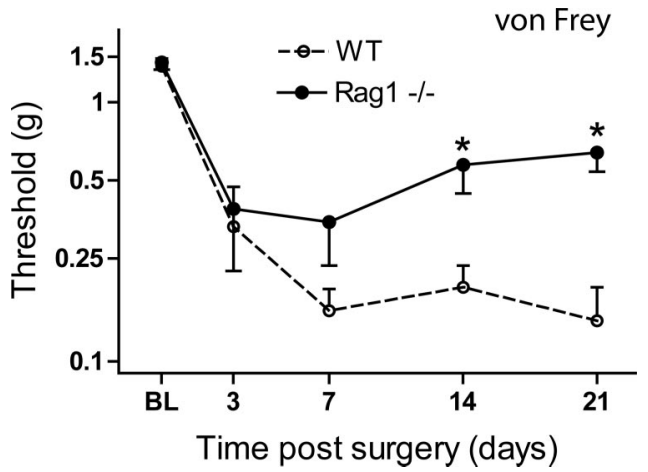

Figure 5. Mechanical sensitivity after SNI in Rag1-null animals relative to wild-type littermate controls. Rag1-null mice develop significantly less mechanical sensitivity in the SNI model over a 3 week time course, compared with wild-type littermate controls. All data are mean \pm SEM. All values are expressed as means \pm SEM. Data were analyzed using two-way ANOVA (time and genotype) for genotype $\left(F_{(1,4)}=5.3 ; p<0.05\right.$; post hoc Student's $t$ test, ${ }^{*} p<0.05$, $n=9$ animals per group).

Table 1. Expression of T-cell-associated cytokines in the neonatal and adult dorsal horn 1 week after SNI

\begin{tabular}{llcc}
\hline Cytokine & $\begin{array}{l}\text { Preferential } \\
\text { cell expression }\end{array}$ & $\begin{array}{l}\text { Fold } \\
\text { (Ad SNI/Ad naive) }\end{array}$ & $\begin{array}{l}\text { Fold } \\
\text { (Ad SNI/Neo SNI) }\end{array}$ \\
\hline IL2 & Th1 & $3.6 \pm 0.5$ & $350 \pm 61$ \\
IFN $\gamma$ & Th1 & $5 \pm 0.9$ & $214 \pm 44$ \\
TNF $\beta$ & Th1 & $1.7 \pm 0.2$ & $7 \pm 0.8$ \\
IL4 & Th2 & $3.6 \pm 0.7$ & $103 \pm 23$ \\
IL5 & Th2 & $0.7 \pm 0.1$ & $0.2 \pm 0.1$ \\
IL13 & Th2 & Not detected & Not detected \\
IL17 & Th17 & $7.6 \pm 1.8$ & $5291 \pm 1505$ \\
\hline
\end{tabular}

All values $p<0.05$, Student's $t$ test. $n=3$ per group. Ad, Adult; Neo, neonate.

not neonate (Fig. 2), suggesting Th1 and Th2 signaling. To examine whether $\mathrm{T}$ helper $(\mathrm{Th})$ cells are differentially expressed in the adult dorsal horn after SNI, we measured cytokines preferentially expressed by Th1, Th2, and Th17 cells (Table 1). These data suggest a larger response for each $\mathrm{T}$ helper class in the adult versus neonate, with Th1 and Th17 particularly overexpressed.

\section{Interferon- $\gamma$ signaling in the dorsal horn contributes to} neuropathic pain-like hypersensitivity in the adult rat There is a large differential expression of IFN $\gamma(214$-fold $)$ in the adult relative to the neonate in response to SNI (Table 1). In addition, expression of IFN $\gamma$ increases over time in the adult relative to the neonate (Fig. $6 a$ ). IFN $\gamma$ is primarily expressed by Th1 T-cells but also NK cells to a lesser extent (Schoenborn and Wilson, 2007).

IFN $\gamma \mathrm{R} 1 \mathrm{mRNA}$ levels are upregulated in both the neonate and adult; however, the extent in the neonate is less than in the adult (Fig. 6b). To test whether IFN $\gamma$ signaling through IFN $\gamma \mathrm{R} 1$ contributes to neuropathic hypersensitivity in the adult, we measured pain-like behavior following SNI in IFN $\gamma R$ 1-null mutants. These mice displayed significantly less mechanical allodynia following SNI than wild-type littermates (Fig. $6 c$ ). We conclude that IFN $\gamma$ signaling plays a role in the immune-driven neuropathic pain sensitivity.

\section{Discussion}

We hypothesized that absence of neuropathic mechanical allodynia in young rats is due to postnatal maturation of specific nerve injury-induced mechanisms that produce hypersensitivity in mature animals. The majority of genes differentially regulated

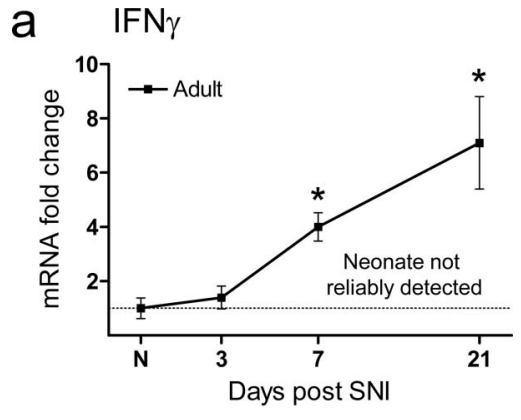

b IFN $\gamma$ R1

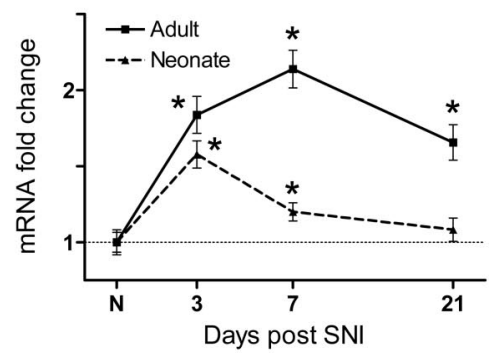

C IFNyR1 -/- von Frey

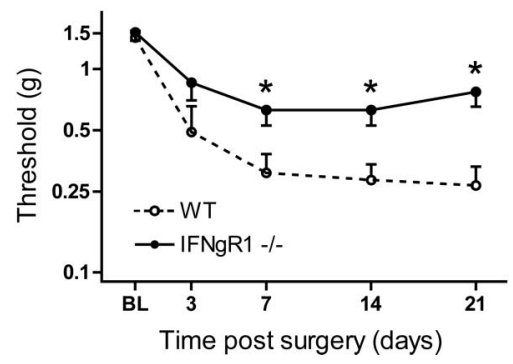

Figure 6. $\boldsymbol{a}$, Expression analysis of the IFN $\gamma$ mRNA by quantitative PCR reveals little evidence of expression in the injured or age-matched control neonatal dorsal horn, in contrast to the adult, where IFN $\gamma$ mRNA increases successively over time. $\boldsymbol{b}$, IFN $\gamma \mathrm{R} 1 \mathrm{mRNA}$ is upregulated in the neonatal and adult dorsal horn over time after SNl; levels of regulation are, however, considerably reduced in the neonate relative to the adult. Data are expressed as mean fold \pm SEM. ${ }^{*} p<0.05$, one-way ANOVA, Student's $t$ test, $n=4$ per group. c, Mechanical sensitivity over time subsequent to SNI injury in IFN $\gamma R$ R-null animals and wild-type littermate control mice. IFN $\gamma R$ T-null animals display less mechanical allodynia relative to controls. All data are mean \pm SEM. Data were analyzed using two-way ANOVA (time and genotype) for genotype $\left(F_{(1,4)}=10.32 ; p<0.05\right.$; post hoc Student's $t$ test, ${ }^{*} p<0.05, n=7$ animals per group $)$.

in the adult compared with the dorsal horn in neonates in the SNI model are genes with an immune function, suggesting that immune cell activation and/or infiltration in the dorsal horn following peripheral nerve injury is lacking in neonates. There is reduced microglial signaling in the young dorsal horn compared with adult (Moss et al., 2007), and this corresponds with reduced activation of antigen presentation pathways (Moss et al., 2007), p38 signaling (Ji and Suter, 2007), the Erk cascade (Zhuang et al., 2005), and CD68 (ED1) expression (Hu et al., 2007). Activation of microglia by chemokines, purines, cytokines, and complement anaphylatoxins (DeLeo and Yezierski, 2001; Watkins et al., 2001; DeLeo et al., 2004; Tsuda et al., 2005; Griffin et al., 2007; Latremoliere et al., 2008) leads to release of signal molecules (Coull et al., 2005; Marchand et al., 2005) that alter excitability or synaptic transmission in the dorsal horn.

Immature dorsal horn neurons are capable of responding to immune activation. Microglial activation and significant allodynia can be evoked by spinal injections of lipopolysaccharide 
(LPS) or NMDA or the intrathecal application of exogenous ATP-stimulated microglia at young ages when peripheral nerve injury has no effect (Moss et al., 2007). These data suggest that the resident immune system in young animals fails to mount the response to nerve injury that in the adult leads to neuropathic pain-like hypersensitivity. This deficiency is likely to include diminished T-cell activation and infiltration. Both young and adult animals have few CD2-positive T-cells before injury, but while these cell increase markedly in adults after SNI, this does not occur in young animals. This is paralleled by a lack of upregulation of CD2 or CD3 mRNA. T-cell levels in the neonate are lower relative to the adult in many tissues (Adkins et al., 2004; Morein et al., 2007), and the type of T-cells that respond to an insult varies in young and adult animals, with a Th2 T-cell bias in the neonate and a predominantly Th1 T-cell response in the adult (Forsthuber et al., 1996; Ridge et al., 1996; Sarzotti et al., 1996). This difference is likely to allow tolerance to new antigens in young animals, and prevents potentially self-damaging inflammation (Adkins et al., 2004). Numerous experiments have shown, however, that if provoked, the young immune system is capable of mounting adult-like responses (Adkins et al., 2004; Morein et al., 2007). Viewed in this context, it is possible to explain the fact that neonates do not respond to peripheral nerve injury, but do respond to centrally applied LPS where the insult is above threshold (Moss et al., 2007).

The functional role of T-cell activation and infiltration in generating neuropathic hypersensitivity in the adult was confirmed using two T-cell-deficient strains of mice; nude animals do not develop neuropathic mechanical hypersensitivity, and mechanical hypersensitivity in the Rag1-null mouse is considerably blunted. Nude mice are the result of a spontaneous mutation of the Foxn1, forkhead box N1 gene (Nehls et al., 1994), which results in T-cell deficiency and a partial defect in B-cell production (Kaushik et al., 1995). Rag1-null animals are the result of a targeted disruption of recombination activating gene 1 (Rag1), and these animals are completely $\mathrm{T}$ - and B-cell deficient (Mombaerts et al., 1992). Our finding of normal neuropathic behavior in B-cell-deficient mice is consistent with previous reports showing that B-cells are not present in the dorsal horn following nerve injury (Cao and DeLeo, 2008). NK cell signaling is present in the adult dorsal horn from our gene list analysis. NK cells act like cytotoxic T-cells to destroy any cell not displaying a MHC class I tag (used to denote self) but differ in that they do not require an antigen interaction to effect their action. NK cells are part of the innate immune system, and their potential role in the central immune response to peripheral nerve injury needs to be explored further; however, that nude and Rag1-null animals have intact NK signaling argues against a prominent role for these cells in determining neuropathic sensitivity (Clark et al., 1981; Croy et al., 2001; Grundy and Sentman, 2006).

Cao and DeLeo (2008) showed a role for CD4-positive T-lymphocytes in producing neuropathic sensitivity. However, the fact that CD4 is also expressed in macrophages/microglia complicates the situation. These authors also noted a recovery to sham levels of sensitivity $5 \mathrm{~d}$ after L5 spinal nerve transection in nude mice on a BALB/c background, which is in good agreement with data presented here using nude mice on a C57BL/6j background in the SNI model.

Peripheral immune cells, including T-cells and macrophages, are likely recruited in proximity to the central terminals of injured afferents by chemoattraction, with the leukocytes traveling across concentration gradients of chemokines and cytokines released by injured axons (White et al., 2007). T-cells enter the CNS though the blood brain barrier by leukocyte extravasation, a process that involves immune cell rolling adhesion followed by tight adhesion and culminating in endothelial cell transmigration (Engelhardt, 2006). Leukocyte extravasation occurs at low levels normally, with the peripheral immune system operating a surveillance role in the CNS. Following injury, however, the process can be substantially elevated. In multiple sclerosis (MS), for instance, T-cells localize to sites of CNS demyelination, and these patients often suffer from neuropathic pain, usually in the form of trigeminal neuralgia (O'Connor et al., 2008). In the experimental autoimmune encephalomyelitis model of MS, the development of neuropathic pain-like hypersensitivity coincides with T-cell infiltration into the dorsal horn (Olechowski et al., 2009).

$\mathrm{T}$-cells orchestrate the adaptive immune response, signaling between MHC class II-expressing antigen-presenting cells (microglia, macrophages, and dendritic cells) and downstream adaptive immune functions. Th cells direct the action of B-cells, NK cells, and phagocytes, whereas cytotoxic T-cells are involved in the destruction of target cells using class I-restricted lysis of antigen-specific targets. Although CD4 and CD8 are both upregulated in the adult dorsal horn after injury, the presence of $\mathrm{CD} 4+\mathrm{CD} 8+$ cytotoxic T-cells cannot be proven here, as both are nonspecific markers when assayed alone. We show a differential increased expression of IFN $\gamma$, IL4, and IL17 in response to nerve injury in adult animals. Th1 cells are involved in the "cellular immunity response" while Th2 cells are involved in "humoral immunity" or antibody production. Excessive Th1-mediated proinflammatory responses can lead to uncontrolled tissue damage, and Th2 can counteract this (Kidd, 2003).

T-cells infiltrate into the injured sciatic nerve following CCI, and athymic nude rats display significantly less neuropathic sensitivity, which can be restored by passive transfer of Th1 but not Th2 T-cells (Moalem et al., 2004). In these CCI-injured animals, Th2 T-cells reduce hypersensitivity, while Th1 T-cells have no additional effect on hypersensitivity levels. While relatively deficient in both $\mathrm{T}$ helper cell classes, neonatal animals have a larger Th2 than Th1 response (Forsthuber et al., 1996; Adkins et al., 2004; Morein et al., 2007). Th17 cells primarily produce IL-17, which is involved in the recruitment, activation, and migration of neutrophils (Weaver et al., 2006; Chen and O'Shea, 2008). IL17 is expressed in T-cells in the injured sciatic nerve in the mouse (Kleinschnitz et al., 2006).

We show a differential expression of IFN $\gamma$ signaling between the adult and neonate, and demonstrate a functional role for IFN $\gamma$ signaling in producing pain-like hypersensitivity in the adult following nerve injury. IFN $\gamma$ is expressed predominantly by Th1 T-cells, but is also found in NK cells (Schroder et al., 2004; Schoenborn and Wilson, 2007). Intrathecal injection of IFN $\gamma$ into the spinal cord elicits hyperalgesia in naive animals (Xu et al., 1994; Vikman et al., 2005). IFN $\gamma \mathrm{R}$ is expressed in neuronal profiles in the superficial layers of the dorsal horn (Vikman et al., 1998), and IFN $\gamma$ sensitizes dorsal horn neurons (Vikman et al., 2003, 2005). Furthermore, IFN $\gamma R$-null animals display reduced nerve injury-induced autotomy (Robertson et al., 1997). We now find that IFN $\gamma R$ 1-null animals have reduced mechanical hypersensitivity following SNI, and that expression of the receptor and ligand are both upregulated in response to a peripheral nerve injury in the adult. These results confirm recently published data by Tsuda et al. (2009) that demonstrate that IFN $\gamma$ stimulates microglia through the IFN $\gamma \mathrm{R}$ and that interfering with this signaling inhibited neuropathic mechanical hypersensitivity. Here we extend these findings by suggesting a source of the IFN $\gamma$ and extending the behavior to 3 weeks. Interestingly IFN $\gamma R$ knock- 
out animals improve progressively with time (Tsuda et al., 2009), a finding consistent with the time-dependent increase in T-cells in the cord, which release IFN $\gamma$, which can then interact with microglia to elicit pain-like sensitivity. The transcript for IFN $\gamma \mathrm{R} 1$ is regulated in the neonatal dorsal horn even though the mRNA for its ligand IFN $\gamma$ is not present at appreciable levels in this tissue. This suggests a ligand other than IFN $\gamma$ signaling through this receptor complex in the injured neonate; alternatively, IFN $\gamma$ may be produced in a tissue other than the dorsal horn.

We conclude that the low-level predominantly Th2-mediated neonatal adaptive immune response does not elicit pain-like responses after nerve injury, while in the adult the high-level, Th1skewed T-cell response leads to pain-like hypersensitivity. Although the exact contributions of infiltrating Th1, Th2, and Th17 cells remain to be determined, the differential T-cell response in the neonate and adult defines a role for these cells in the generation of neuropathic pain after peripheral nerve injury in the adult. Treatment strategies that target recruitment of T-cells into the CNS may therefore help combat establishment of neuropathic pain hypersensitivity in man.

\section{References}

Adkins B, Leclerc C, Marshall-Clarke S (2004) Neonatal adaptive immunity comes of age. Nat Rev Immunol 4:553-564.

Beggs S, Salter MW (2007) Stereological and somatotopic analysis of the spinal microglial response to peripheral nerve injury. Brain Behav Immun 21:624-633.

Bennett GJ, Xie YK (1988) A peripheral mononeuropathy in rat that produces disorders of pain sensation like those seen in man. Pain 33:87-107.

Cao L, DeLeo JA (2008) CNS-infiltrating CD4(+) T lymphocytes contribute to murine spinal nerve transection-induced neuropathic pain. Eur J Immunol 38:448-458.

Chen Z, O'Shea JJ (2008) Regulation of IL-17 production in human lymphocytes. Cytokine 41:71-78.

Clark EA, Shultz LD, Pollack SB (1981) Mutations in mice that influence natural killer (NK) cell activity. Immunogenetics 12:601-613.

Costigan M, Befort K, Karchewski L, Griffin RS, D’Urso D, Allchorne A, Sitarski J, Mannion JW, Pratt RE, Woolf CJ (2002) Replicate highdensity rat genome oligonucleotide microarrays reveal hundreds of regulated genes in the dorsal root ganglion after peripheral nerve injury. BMC Neurosci 3:16.

Costigan M, Scholz J, Woolf CJ (2009) Neuropathic pain: a maladaptive response of the nervous system to damage. Annu Rev Neurosci 32:1-32.

Coull JA, Beggs S, Boudreau D, Boivin D, Tsuda M, Inoue K, Gravel C, Salter MW, De Koninck Y (2005) BDNF from microglia causes the shift in neuronal anion gradient underlying neuropathic pain. Nature 438:1017-1021.

Croy BA, Linder KE, Yager JA (2001) Primer for non-immunologists on immune-deficient mice and their applications in research. Comp Med 51:300-313.

Decosterd I, Woolf CJ (2000) Spared nerve injury: an animal model of persistent peripheral neuropathic pain. Pain 87:149-158.

DeLeo JA, Yezierski RP (2001) The role of neuroinflammation and neuroimmune activation in persistent pain. Pain 90:1-6.

DeLeo JA, Tanga FY, Tawfik VL (2004) Neuroimmune activation and neuroinflammation in chronic pain and opioid tolerance/hyperalgesia. Neuroscientist 10:40-52.

Echeverry S, Shi XQ, Zhang J (2008) Characterization of cell proliferation in rat spinal cord following peripheral nerve injury and the relationship with neuropathic pain. Pain 135:37-47.

Engelhardt B (2006) Molecular mechanisms involved in T cell migration across the blood-brain barrier. J Neural Transm 113:477-485.

Forsthuber T, Yip HC, Lehmann PV (1996) Induction of TH1 and TH2 immunity in neonatal mice. Science 271:1728-1730.

Gentleman RC, Carey VJ, Bates DM, Bolstad B, Dettling M, Dudoit S, Ellis B, Gautier L, Ge Y, Gentry J, Hornik K, Hothorn T, Huber W, Iacus S, Irizarry R, Leisch F, Li C, Maechler M, Rossini AJ, Sawitzki G, et al. (2004) Bioconductor: open software development for computational biology and bioinformatics. Genome Biol 5:R80.
Griffin RS, Costigan M, Brenner GJ, Ma CH, Scholz J, Moss A, Allchorne AJ, Stahl GL, WoolfCJ (2007) Complement induction in spinal cord microglia results in anaphylatoxin C5a-mediated pain hypersensitivity. J Neurosci 27:8699-8708.

Grundy MA, Sentman CL (2006) Immunodeficient mice have elevated numbers of NK cells in non-lymphoid tissues. Exp Cell Res 312:39203926.

Hedo G, Laird JM, Lopez-Garcia JA (1999) Time-course of spinal sensitization following carrageenan-induced inflammation in the young rat: a comparative electrophysiological and behavioural study in vitro and in vivo. Neuroscience 92:309-318.

Howard RF, Hatch DJ, Cole TJ, Fitzgerald M (2001) Inflammatory pain and hypersensitivity are selectively reversed by epidural bupivacaine and are developmentally regulated. Anesthesiology 95:421-427.

Howard RF, Walker SM, Mota PM, Fitzgerald M (2005) The ontogeny of neuropathic pain: postnatal onset of mechanical allodynia in rat spared nerve injury (SNI) and chronic constriction injury (CCI) models. Pain 115:382-389.

Hu P, Bembrick AL, Keay KA, McLachlan EM (2007) Immune cell involvement in dorsal root ganglia and spinal cord after chronic constriction or transection of the rat sciatic nerve. Brain Behav Immun 21:599-616.

Ji RR, Suter MR (2007) p38 MAPK, microglial signaling, and neuropathic pain. Mol Pain 3:33.

Kaushik A, Kelsoe G, Jaton JC (1995) The nude mutation results in impaired primary antibody repertoire. Eur J Immunol 25:631-634.

Kawasaki Y, Xu ZZ, Wang X, Park JY, Zhuang ZY, Tan PH, Gao YJ, Roy K, Corfas G, Lo EH, Ji RR (2008) Distinct roles of matrix metalloproteases in the early- and late-phase development of neuropathic pain. Nat Med 14:331-336.

Kidd P (2003) Th1/Th2 balance: the hypothesis, its limitations, and implications for health and disease. Altern Med Rev 8:223-246.

Kim SH, Chung JM (1992) An experimental model for peripheral neuropathy produced by segmental spinal nerve ligation in the rat. Pain 50:355-363.

Kleinschnitz C, Hofstetter HH, Meuth SG, Braeuninger S, Sommer C, Stoll G (2006) T cell infiltration after chronic constriction injury of mouse sciatic nerve is associated with interleukin-17 expression. Exp Neurol 200:480-485

Lacroix-Fralish ML, Tawfik VL, Tanga FY, Spratt KF, DeLeo JA (2006) Differential spinal cord gene expression in rodent models of radicular and neuropathic pain. Anesthesiology 104:1283-1292.

Latremoliere A, Mauborgne A, Masson J, Bourgoin S, Kayser V, Hamon M, Pohl M (2008) Differential implication of proinflammatory cytokine interleukin-6 in the development of cephalic versus extracephalic neuropathic pain in rats. J Neurosci 28:8489-8501.

Marchand F, Perretti M, McMahon SB (2005) Role of the immune system in chronic pain. Nat Rev Neurosci 6:521-532.

Moalem G, Xu K, Yu L (2004) Tlymphocytes play a role in neuropathic pain following peripheral nerve injury in rats. Neuroscience 129:767-777.

Mombaerts P, Iacomini J, Johnson RS, Herrup K, Tonegawa S, Papaioannou VE (1992) RAG-1-deficient mice have no mature B and T lymphocytes. Cell 68:869-877.

Morein B, Blomqvist G, Hu K (2007) Immune responsiveness in the neonatal period. J Comp Pathol 137 [Suppl 1]:S27-S31.

Moss A, Beggs S, Vega-Avelaira D, Costigan M, Hathway GJ, Salter MW, Fitzgerald M (2007) Spinal microglia and neuropathic pain in young rats. Pain 128:215-224.

Nehls M, Pfeifer D, Schorpp M, Hedrich H, Boehm T (1994) New member of the winged-helix protein family disrupted in mouse and rat nude mutations. Nature 372:103-107.

O'Connor AB, Schwid SR, Herrmann DN, Markman JD, Dworkin RH (2008) Pain associated with multiple sclerosis: systematic review and proposed classification. Pain 137:96-111.

Olechowski CJ, Truong JJ, Kerr BJ (2009) Neuropathic pain behaviours in a chronic-relapsing model of experimental autoimmune encephalomyelitis (EAE). Pain 141:156-164.

R Development Core Team (2005) R: a language and environment for statistical computing. Vienna: R Foundation for Statistical Computing.

Ridge JP, Fuchs EJ, Matzinger P (1996) Neonatal tolerance revisited: turning on newborn T cells with dendritic cells. Science 271:1723-1726.

Ririe DG, Eisenach JC (2006) Age-dependent responses to nerve injuryinduced mechanical allodynia. Anesthesiology 104:344-350. 
Robertson B, Xu XJ, Hao JX, Wiesenfeld-Hallin Z, Mhlanga J, Grant G, Kristensson K (1997) Interferon-gamma receptors in nociceptive pathways: role in neuropathic pain-related behaviour. Neuroreport 8:1311-1316.

Sarzotti M, Robbins DS, Hoffman PM (1996) Induction of protective CTL responses in newborn mice by a murine retrovirus. Science 271:1726-1728.

Schoenborn JR, Wilson CB (2007) Regulation of interferon-gamma during innate and adaptive immune responses. Adv Immunol 96:41-101.

Schroder K, Hertzog PJ, Ravasi T, Hume DA (2004) Interferon-gamma: an overview of signals, mechanisms and functions. J Leukoc Biol 75:163-189.

Seltzer Z, Dubner R, Shir Y (1990) A novel behavioral model of neuropathic pain disorders produced in rats by partial sciatic nerve injury. Pain 43:205-218.

Smyth G (2005) Limma: linear models for microarray data. In: Bioinformatics and computational biology solutions using $\mathrm{R}$ and bioconductor (Gentleman R, Carey V, Huber W, Irizarry R, Dudoit S, eds), pp 397-420. New York: Springer.

Torsney C, Fitzgerald M (2002) Age-dependent effects of peripheral inflammation on the electrophysiological properties of neonatal rat dorsal horn neurons. J Neurophysiol 87:1311-1317.

Tsuda M, Inoue K, Salter MW (2005) Neuropathic pain and spinal microglia: a big problem from molecules in "small" glia. Trends Neurosci 28:101-107.

Tsuda M, Masuda T, Kitano J, Shimoyama H, Tozaki-Saitoh H, Inoue K (2009) IFN-gamma receptor signaling mediates spinal microglia activation driving neuropathic pain. Proc Natl Acad Sci U S A 106:8032-8037.

Vega-Avelaira D, Moss A, Fitzgerald M (2007) Age-related changes in the spinal cord microglial and astrocytic response profile to nerve injury. Brain Behav Immun 21:617-623.

Vikman K, Robertson B, Grant G, Liljeborg A, Kristensson K (1998) Interferon-gamma receptors are expressed at synapses in the rat superficial dorsal horn and lateral spinal nucleus. J Neurocytol 27:749-759.
Vikman KS, Hill RH, Backström E, Robertson B, Kristensson K (2003) Interferon-gamma induces characteristics of central sensitization in spinal dorsal horn neurons in vitro. Pain 106:241-251.

Vikman KS, Siddall PJ, Duggan AW (2005) Increased responsiveness of rat dorsal horn neurons in vivo following prolonged intrathecal exposure to interferon-gamma. Neuroscience 135:969-977.

Walker SM, Howard RF, Keay KA, Fitzgerald M (2005) Developmental age influences the effect of epidural dexmedetomidine on inflammatory hyperalgesia in rat pups. Anesthesiology 102:1226-1234.

Watkins LR, Milligan ED, Maier SF (2001) Glial activation: a driving force for pathological pain. Trends Neurosci 24:450-455

Weaver CT, Harrington LE, Mangan PR, Gavrieli M, Murphy KM (2006) Th17: an effector CD4 T cell lineage with regulatory T cell ties. Immunity 24:677-688.

White FA, Jung H, Miller RJ (2007) Chemokines and the pathophysiology of neuropathic pain. Proc Natl Acad Sci U S A 104:20151-20158.

Wu ZI, Irizarry RA, Gentleman R, Martinez-Murillo F, Spencer F (2004) A model-based background adjustment for oligonucleotide expression arrays. J Am Stat Assoc 99:909-917.

Xu XJ, Hao JX, Olsson T, Kristensson K, van der Meide PH, WiesenfeldHallin Z (1994) Intrathecal interferon-gamma facilitates the spinal nociceptive flexor reflex in the rat. Neurosci Lett 182:263-266.

Yang L, Zhang FX, Huang F, Lu YJ, Li GD, Bao L, Xiao HS, Zhang X (2004) Peripheral nerve injury induces trans-synaptic modification of channels, receptors and signal pathways in rat dorsal spinal cord. Eur J Neurosci 19:871-883.

Zhuang ZY, Gerner P, Woolf CJ, Ji RR (2005) ERK is sequentially activated in neurons, microglia, and astrocytes by spinal nerve ligation and contributes to mechanical allodynia in this neuropathic pain model. Pain 114: $149-159$. 